\title{
Perceptions of Students Learning French as a Foreign Language in Malaysia
}

\author{
RODOLPHE GILLES POINT, CHIA-CHUN NG \& SU-HIE TING*
}

Faculty of Language and Communication, Universiti Malaysia Sarawak, 94300 Kota Samarahan, Sarawak, Malaysia *Corresponding Author: shting@unimas.my

\begin{abstract}
The study investigated the perceptions of students learning French as a foreign language in a Malaysian public university. The specific objectives were to examine: (1) the self-reported French language proficiency level; and (2) their perceptions of their listening, speaking, reading and writing skills in French. Questionnaire data were collected from 80 undergraduates enrolled in French Levels 1 and 2 courses. The analysis showed that language learners from Level 1 and Level 2 rated themselves as having fair proficiency level when they made their rating without comparing themselves to a French native speaker. However, when they compared themselves with a native French speaker, more of them rated their proficiency as poor. The results showed that the relative difficulty of mastering language skills in French, from the most difficult to the easiest, are writing, speaking, reading and listening. Similar results were found for Level 1 and Level 2 French but the undergraduates struggled with writing and speaking at Level 2 more than at Level 1 because of an increased vocabulary range, greater grammatical complexity and longer texts. The results suggest that the difficulties are not much in comprehension of the language but more towards expressing themselves whether in speaking or writing.
\end{abstract}

Keywords: French language proficiency, Learning French as a Foreign Language

Copyright: This is an open access article distributed under the terms of the CC-BY-NC-SA (Creative Commons Attribution-NonCommercial-ShareAlike 4.0 International License) which permits unrestricted use, distribution, and reproduction in any medium, for non-commercial purposes, provided the original work of the author(s) is properly cited.

\section{INTRODUCTION}

Foreign languages are learnt for various reasons ranging from personal enrichment to fulfilling job requirements involving the use of foreign languages, particularly in the era of rapid economic and technological development. Proficiency in foreign languages increases the competitiveness of graduates (e.g., better work opportunities and higher salary potential) in a workplace where global communication is increasingly becoming seamless. On a personal level, learning a foreign language enables language learners to expand their worldview and develop a deeper understanding of other cultures (Tar, 2011).

Foreign language learning can be defined as the "learning of non-native language outside of the environment where it is commonly spoken" (Moeller \& Catalano, 2015). A foreign language is a language which is taught in a society where the language is not spoken as a native language (Gass \& Schachter, 1989), and the language is learned in a classroom situation (Moeller \& Catalano, 2015). For instance, French, Japanese, Arabic and Korean are taught as foreign languages in Malaysia. The foreign language is primarily for communication with people outside one's own community unlike a language which has social functions inside the community (Littlewood, 1984).

This paper focusses on French. French is considered as the second most studied world language after English, and it is an official language in 29 countries with about 76 million native French speakers and 274 million fluent French speakers worldwide (World Population Review, 2021). According to Chinedu and Anthonia (2015), French is one of the most spoken Romance languages that has been used as a language of instruction in most of the countries. French language is one of the languages used in meetings by the United Nations Organization and other international organisations (Adewuyi, Bernard \& Adewuyi, 2015). 